\section{Epigenetics or ephemeral genetics?}

European Journal of Human Genetics (2006) 14, 1149. doi:10.1038/sj.ejhg.5201683; published online 12 July 2006

The paper by Kaati et al ${ }^{1}$ claiming to show that a surfeit of food during a paternal grandfather's slow growth period could lead to an increased risk of death from diabetes continues to attract interest in this journal. ${ }^{2}$ I believe, however, that the analysis of the data reported is inappropriate or at the very least inadequately described as regards a number of aspects and that, pending valid analysis or clarification, these epigenetic claims should be treated with caution.

The first point is that it seems highly probable that some of the 239 probands analysed had two or more grandparents in common, that is to say that some probands were siblings or first cousins of each other. The fact that sampling was performed by birth year 1890, 1905 or 1920 may reduce the number of consanguinities, in particular siblings, and of course the $50 \%$ sample will contribute further to this, but some discussion of this point is owed to the reader. If it is the case that some probands are cousins, then the observations cannot be treated as independent, but must be seen as repeated measures on the grandparent in question. In fact, a satisfactory model may require several stages of hierarchy. It is well known that treating correlated observations as independent leads to 'spurious precision' with artificially low standard errors and $P$-values and confidence intervals that are too narrow. A highly relevant analogous field to epigenetics is that of teratology. Here it is well understood that when toxicological experiments are carried out on pregnant rats, the resulting pups must be treated as repeated measures on the dams ${ }^{3}$ and mixed models are needed. ${ }^{4}$ Failure to analyse data in this way is to regard two cousins, both of whom died of diabetes and whose common paternal grandfather had a surfeit of food in his slow growth period as providing the same evidence as two unrelated probands dying of diabetes, each of whose two paternal grandparents had a surfeit of food in their slow growth period.

The second point is that where so many possible hypotheses are being investigated, it is inappropriate to concentrate only on those which after the fact turn out to have 'significant' results attached to them. If this is to be done, then some sort of adjustment for multiplicity ought to be applied, most simply, but not necessarily most appropriately, using a Bonferroni correction. If such adjustments are not performed, then the totality of the evidence has to be accepted and the fact that many specific individual null hypotheses investigated were not rejected calls for caution as regards accepting any particular variant of the epigenetic hypothesis. (see Senn, 1997, Chapter 10 for a discussion of these issues ${ }^{5}$ ).

Finally, in the multiple regression model used by Kaati et $\mathrm{al}^{1}$ age at death has been included as a predictor variable. This is a conceptual error that tends in the opposite direction to the first two. Age at death is (at least partially) an outcome of the disease process. Diabetics may be expected to die younger than those who are healthy. Thus, age at death cannot naively be used as a predictor variable.

In short, while Kaati et al ${ }^{1}$ have collected some interesting data, researchers should be extremely cautious, pending further clarification, in accepting their conclusion that 'these epidemiological findings draw attention to the transgenerational effects down the male line of nutritionrelated circumstances during a period of childhood' (p. 688).

Stephen Senn*,1
${ }^{1}$ Department of Statistics, University of Glasgow, Glasgow, UK
*Correspondence: Professor S Senn, Department of Statistics,
University of Glasgow, 15 University Gardens, Glasgow G12
$8 Q Q$ UK.
Tel: $+441413305141 ;$
Fax: $+441413304814 ;$
E-mail: stephen@stats.gla.ac.uk

\section{References}

1 Kaati G, Bygren LO, Edvinsson S: Cardiovascular and diabetes mortality determined by nutrition during parents' and grandparents' slow growth period. Eur J Hum Genet 2002; 10: 682-688.

2 Whitelaw E: Sins of the fathers, and their fathers. Eur J Hum Genet 2006; 14: 131-132.

3 Senn SJ: Statistical test. New Scientist 1981; 90: 581.

4 Dempster AP, Patel CM, Selwyn MR, Roth AJ: Statistical and computational aspects of mixed model analysis. Appl Stat-J R Stat Soc Series C 1984; 33: 203-214.

5 Senn SJ: Statistical Issues in Drug Development. Chichester: Wiley, 1997, p. 405.

\section{Reply to Senn}

European Journal of Human Genetics (2006) 14, 1149-1150. doi:10.1038/sj.ejhg.5201685; published online 12 July 2006

Stephen Senn's first point is a valid one and we are grateful for the opportunity to clarify the situation. The 2002 
paper $^{1}$ should have stated the relationships between probands. This information is not only relevant to the statistical analysis as he points out but also to the issue of whether there might have been selection for a genetic variant carried by survivors of the grandparental generation that predisposes to diabetes in the probands generation. The relationship was checked regarding the 19 diabetic probands and they all had different paternal grandfathers. The nondiabetic probands could have been related, falsely narrowing the confidence intervals, but sensitivity analyses by randomly keeping just one cousin (where cousin relationship existed) does not change results significantly.

With respect to Senn's point about mass significance, we did not screen a lot of variables describing the same factor, we only ruled out confounding between ancestors. There were few hypotheses tested. The type of exposure (food supply) and the timing of exposure (slow growth period) had been selected on the basis of earlier work. ${ }^{2}$ Only two outcomes were tested, cardiovascular and diabetic deaths, both prior hypotheses.

Senn's third point relates to the control of age. At first glance, an outcome variable was used as predictor, but the outcome was not death but cause of death. As we knew that the paternal grandparents 'starving' during the slow growth period, when they were around 10-11 years old, was followed by a long life of the probands, we were careful not to overstate the probands cardiovascular and diabetes mortality, causes of death that have become so common during aging.

It is early days in the study of male-line transgenerational responses in humans, but some coherence is emerging with respect to observed outcomes. They have features of the Metabolic Syndrome, which some regard as a 'maladaptation' to a modern world. ${ }^{3}$ In addition to the cardiovascular and diabetic risks observed in the Överkalix cohort, the contemporary ALSPAC cohort has found an association between mid-childhood paternal smoking and a raised body mass index in sons ${ }^{4}$ and in Taiwan paternal betel nut (Areca catechu) chewing has been linked to early onset of the metabolic syndrome in the offspring. ${ }^{5}$ Still our findings were both significant and nonsignificant and more human replicating data are necessary.

Finally, we should emphazise that we do not claim that these transgenerational responses are mediated by epigenetic inheritance (ie where the DNA sequence itself is unchanged), only that this mechanism is a good candidate.

Lars Olov Bygren*, ${ }^{*}$, Gunnar Kaati ${ }^{1}$, Sören Edvinsson ${ }^{2}$ and Marcus E Pembrey ${ }^{3}$

${ }^{1}$ Department of Community Medicine and Rehabilitation, Social Medicine, Umea University, Umeå, Sweden;

${ }^{2}$ Demographic Database, Umea University, Umeå, Sweden;

${ }^{3}$ Clinical and Molecular Genetics Unit, Institute of Child Health, University College London, UK

${ }^{*}$ Correspondence: LO Bygren, Department of Biosciences, Preventive Nutrition, Huddinge, Karolinska Institute, Sweden. Tel.: + $46(0) 86083300$; Fax: + $46(0) 86083350$;

E-mail: lars-olov.bygren@biosci.ki.se

\section{References}

1 Kaati G, Bygren LO, Edvinsson S: Cardiovascular and diabetes mortality determined by nutrition during parents' and grandparents' slow growth period. Eur J Hum Genet 2002; 10: 682-688.

2 Bygren LO, Kaati G, Edvinsson S: Longevity determined by ancestors' overnutrition during their slow growth period. Acta Biotheoret 2001; 49: 53-59.

3 Wilkin TJ, Voss LD: Metabolic syndrome: maladaptation to a modern world. J R Soc Med 2004; 97: 511-520.

4 Pembrey ME, Bygren LO, Kaati G et al: Sex-specific, male-line transgenerational responses in humans. Eur J Hum Genet 2006; 14: 159-166.

5 Chen THH, Chiu YH, Boucher BJ: Transgenerational effects of betal quid chewing on the development of the metabolic syndrome in the Keelung Community-based Integrated Screening Program. Am J Clin Nutr 2006; 83: 688-692. 